\title{
KINERJA SISA UMUR RENCANA JALAN \\ BERDASARKAN PERTUMBUHAN LALU LINTAS DI KOTA PALANGKA RAYA
}

\author{
Robby Bagaskara ${ }^{1}$, Desi Riani ${ }^{2}$ dan $_{\text {Murniati }}{ }^{3}$ \\ ${ }^{123}$ Program Studi Teknik Sipil, Fakultas Teknik, Universitas Palangka Raya \\ E-mail: bagaskararobby@ gmail.com¹, desiriani@jts.upr.ac.id ${ }^{2}$,dan \\ murniati-upr@eng.upr.ac.id ${ }^{3} /$ HP.+6282256582682 ${ }^{1}$
}

\begin{abstract}
ABSTRAK
Perubahan volume lalu lintas pada ruas jalan Rajawali di kota Palangka Raya memberikan dampak terhadap kondisi jalan dan umur jalan. Penelitian ini bertujuan untuk mengetahui sisa umur jalan dan untuk mengetahui besarnya nilai derajat kerusakan pada jalan. Pengumpulan data LHR diperoleh dari hasil survei di lapangan. Perhitungan sisa umur jalan menggunakan metode Bina Marga 2013 dan AASHTO 1993, yang diperoleh dari nilai jumlah kendaraan dan nilai Equivalent Standard Axle Load (ESAL) kendaraan dalam keadaan normal. Berdasarkan hasil analisis sisa umur rencana jalan, pada ruas jalan Rajawali dari arah Segmen (Simpang 4 Tingang - Rajawali) mempunyai sisa umur yaitu 66,95 $\%$ dan dari jalan Rajawali dari arah Segmen (Simpang 4 Badak - Rajawali) mempunyai sisa umur yaitu $71,86 \%$. Dari hasil perhitungan nilai derajat kerusakan jalan pada kendaraan, didapatkan bahwa truk 2 sumbu yang memiliki beban $>20$ ton mengalami overloading karena roda bagian belakang kelebihan 4,8630 sehingga menjadi tidak aman, truk 3 sumbu yang memiliki beban $>30$ ton juga mengalami overloading karena roda bagian belakang kelebihan 5,3810 sehingga menjadi tidak aman, dimana keduanya sama dengan truk yang memiliki 3 - 4 as tunggal yang lewat.
\end{abstract}

Kata Kunci : Sisa Umur Jalan, Kerusakan Dini, LHR

\section{ABSTRACT}

Changes in traffic volume on the Rajawali road in the city of Palangka Raya have an impact on road conditions and road age. This study aims to determine the remaining life of the road and to determine the value of the degree of damage to the road. LHR data collection is obtained from survey results in the field. Calculation of the remaining life of the road using the 2013 Bina Marga and AASHTO 1993 methods, which is obtained from the value of the number of vehicles and the value of the Equivalent Standard Axle Load (ESAL) of the vehicle under normal conditions. Based on the results of the analysis of the remaining life of the road plan, the Rajawali road segment from the Segment direction (Intersection 4 Tingang - Rajawali) has a remaining life of $66.95 \%$ and from the Rajawali road from the Segment direction (Intersection 4 Badak-Rajawali) has a remaining life of $7186 \%$. From the results of the calculation of the value of the degree of road damage on vehicles, it was found that a 2-axis truck with a load of $>20$ tons was overloaded because the rear wheel was overloaded with 4.8630 so that it became unsafe, a 3-axis truck with a load >30 tons also experienced 
overloading due to the wheels. the rear is over 5.3810 making it unsafe, both of which are equivalent to trucks having 3-4 single axles passing.

Keywords: Remaining Road Life, Early Damage, LHR

\section{PENDAHULUAN}

\section{Latar Belakang}

Kota Palangka Raya merupakan salah satu kota yang dewasa ini mengalami pertumbuhan jumlah penduduk. Seiring dengan hal tersebut jalan raya merupakan salah satu prasarana transportasi darat terpenting, sebagai kebutuhan pokok yang menunjang kegiatan masyarakat. Hal ini dikarenakan jalan mempunyai peran penting dalam bidang ekonomi, politik, sosial, budaya, dan hankam. Kota Palangka Raya merupakan salah satu kota yang dewasa ini mengalami pertumbuhan jumlah penduduk. Seiring dengan hal tersebut jalan raya merupakan salah satu prasarana transportasi darat terpenting, sebagai kebutuhan pokok yang menunjang kegiatan masyarakat. Hal ini dikarenakan jalan mempunyai peran penting dalam bidang ekonomi, politik, sosial, budaya, dan hankam. Menurut Arbani (2018), dengan bertambahnya manusia yang berakibat terhadap bertambahnya volume LHR, menyebabkan berpengaruhnya sisa umur jalan yang berlaku serta perubahan volume kendaraan juga mengakibatkan berkurangnya sisa umur jalan. Perkembangan pertumbuhan volume lalu lintas kendaraan bermotor baik roda dua, roda empat maupun lebih semakin meningkat. Beberapa permasalahan pada ruas jalan yang diteliti seperti volume lalu lintas yang padat, banyaknya kerusakan pada perkerasan jalan mengakibatkan berkurangnya umur rencana jalan. Seperti pada ruas jalan Rajawali yang merupakan jalan utama yang berperan penting sebagai penghubung kegiatan nasional, wilayah, lokal, hingga lingkungan yang semuanya berguna untuk perkembangan pembangunan infrastruktur dan perekonomian di kota Palangka Raya. Karena peran yang sangat penting tersebut maka jalan-jalan tersebut menanggung beban lalu lintas yang akan bertambah seiring dengan pertumbuhan volume lalu lintas yang berpengaruh pada umur rencana jalan tersebut.

\section{Tujuan Penelitian}

Dalam penelitian ini bertujuan untuk mengetahui sisa umur jalan dan untuk mengetahui besarnya nilai derajat kerusakan pada jalan.

\section{METODE PENELITIAN}

\section{1) Lokasi dan Teknik Pengambilan Sampel}

Lokasi yang dipilih untuk penelitian yaitu Kota Palangka Raya pada ruas jalan Rajawali. Waktu penelitian berlangsung selama 1 minggu. Penelitian dilakukan pada jam sibuk pukul 06.00-22.00 WIB (16jam) untuk ruas jalan Rajawali berdasarkan survei pendahuluan.

\section{2) Metode Pengambilan Data}

Metode yang dipergunakan adalah bersumber dari Data primer (pengamatan dan pengukuran dilapangan), dan Data sekunder (data dari instansi terkait).

\section{3) Tahapan Penelitian}

Adapun tahapan-tahapan penelitian ini adalah Survei Pendahuluan, Persiapan pelaksanaan penelitian, dan Pelaksanaan penelitian. 


\section{HASIL DAN PEMBAHASAN}

Hasil survei kendaraan yang dilakukan di ruas jalan Kota Palangka Raya yang ditinjau, data tersebut selanjutnya dijabarkan sebagai berikut dalam bentuk tabel. Berikut Rekap Data Eksisting LHR Mingguan dilihat pada Tabel 1 dan Rekap Data Perencanaan LHR untuk 10 tahun kedepan dapat dilihat pada Tabel 2.

Tabel 1. Tabel Rekap Data Eksisting LHR Mingguan

\begin{tabular}{|c|c|c|}
\hline \multicolumn{3}{|c|}{ Rata LHR Jalan Rajawali dari Arah Segmen (Simpang 4 Tingang - } \\
\hline \multirow{2}{*}{ No } & Jenis Kendaraan & Jumlah \\
\cline { 2 - 3 } & Sedan, pick up, angkot, wagon & $\mathbf{2 0 2 1}$ \\
\hline 1 & Bus & 2835 \\
\hline 2 & Truk & 25 \\
\hline 3 & Rajawali) \\
\hline \multicolumn{3}{|c|}{ Data LHR Jalan Rajawali dari Arah Segmen (Simpang 4 Badak - } \\
\hline \multirow{2}{*}{ No } & Jenis Kendaraan & Jumlah \\
\hline 1 & Sedan, pick up, angkot, wagon & 2934 \\
\hline 2 & Bus & 1 \\
\hline 3 & Truk & 28 \\
\hline
\end{tabular}

Dari Tabel 1 diatas dapat di proyeksikan jumlah Lalu lintas Harian Rata-rata (LHR) untuk 10 tahun yang akan datang dengan rumus sebagai berikut. LHRn $=$ LHR0 $x(1+\mathrm{i}) \mathrm{n}$

Tabel 2. Tabel Rekap Data Perencanaan 10 Tahun Kedepan

\begin{tabular}{|c|c|c|c|}
\hline \multicolumn{2}{|c|}{ Data LHR Jalan Rajawali dari Arah Segmen (Simpang 4 Tingang - Rajawali) } \\
\hline \multirow{2}{*}{ No } & \multirow{2}{*}{ Jenis Kendaraan } & \multicolumn{2}{|c|}{ Jumlah } \\
\cline { 3 - 4 } & & $\mathbf{2 0 2 1}$ & $\mathbf{2 0 3 1}$ \\
\hline 1 & Sedan, pick up, angkot, wagon & 2835 & 4196 \\
\hline 2 & Bus & 1 & 1 \\
\hline 3 & Truk & 25 & 37 \\
\hline
\end{tabular}

Data LHR Jalan Rajawali dari Arah Segmen (Simpang 4 Badak - Rajawali)

\begin{tabular}{|c|c|c|c|}
\hline \multirow{2}{*}{ No } & \multirow{2}{*}{ Jenis Kendaraan } & \multicolumn{2}{|c|}{ Jumlah } \\
\cline { 3 - 4 } & & $\mathbf{2 0 2 1}$ & $\mathbf{2 0 3 1}$ \\
\hline 1 & Sedan, pick up, angkot, wagon & 2934 & 4343 \\
\hline 2 & Bus & 1 & 1 \\
\hline 3 & Truk & 28 & 41 \\
\hline
\end{tabular}




\section{1) Angka Pertumbuhan Lalu Lintas}

Angka pertumbuhan lalu lintas didapat dengan melakukan wawancara langsung dari Balai P2JN Kota Palangka Raya. Berdasarkan hasil wawancara dengan pihak Balai P2JN didapat angka pertumbuhan lalu lintas yaitu sebesar 4\% untuk setiap ruas jalan yang dilakukan penelitian.

\section{Nilai ESAL Tahun 2021}

Nilai beban sumbu kendaraan (ESAL) dihitung menggunakan rumus berikut ini :

$$
\mathrm{E}=\text { LHR } \times \text { Nilai VDF }
$$

Maka di dapat hasil seperti di Tabel 3 dan Tabel 4 berikut ini.

Tabel 3. Nilai ESAL Tahun 2021 Jalan Rajawali dari Arah Segmen (Simpang 4 Tingang - Rajawali)

\begin{tabular}{|l|l|l|l|l|}
\hline No & Jenis Kendaraan & LHR 2021 & AE(VDF) & $\begin{array}{l}\text { Nilai } \\
\text { ESAL }\end{array}$ \\
\hline 1 & Sedan, pick up, angkot, wagon & 2835 & 0,0005 & 1,4175 \\
\hline 2 & Bus & 1 & 0,2174 & 0,2174 \\
\hline 3 & Truk & 28 & 2,4134 & 60,335 \\
\hline
\end{tabular}

(ESAL) $W_{18}=\sum_{N_{1}}^{N_{n}} L H R_{j} \times V D F_{j} \times D_{D} \times D_{L} \times 365$

ESAL W18 $=61,9699 \times 0,60 \times 0,8 \times 365$

ESAL $2021=\quad 10857,12648$

Tabel 4. Nilai ESAL Tahun 2021 Jalan Rajawali dari Arah Segmen (Simpang 4 Badak - Rajawali)

\begin{tabular}{|l|l|l|l|l|}
\hline No & Jenis Kendaraan & LHR 2021 & AE(VDF) & $\begin{array}{l}\text { Nilai } \\
\text { ESAL }\end{array}$ \\
\hline 1 & Sedan, pick up, angkot, wagon & 2934 & 0,0005 & 1,467 \\
\hline 2 & Bus & 1 & 0,2174 & 0,2174 \\
\hline 3 & Truk & 28 & 2,4134 & 67,5752 \\
\hline \multicolumn{2}{|l}{} & $\mathbf{6 9 , 2 5 9 6}$ \\
\hline
\end{tabular}

$(\mathrm{ESAL}) W_{18}=\sum_{N_{1}}^{N_{n}} L H R_{j} \times V D F_{j} \times D_{D} \times D_{L} \times 365$

ESAL W18 $=69,2596 \times 0,60 \times 0,8 \times 365$

ESAL $2021=$

12134,28192

Dari tabel diatas maka didapat nilai ESAL 2021 dari ruas jalan yang di tinjau yaitu :

a. Nilai ESAL 2021 di ruas Jalan Rajawali dari Arah Segmen (Simpang 4 Tingang - Rajawali) adalah 10857,12648.

b. Nilai ESAL 2021 di ruas Jalan Rajawali dari Arah Segmen (Simpang 4 Badak - Rajawali) adalah 12134,28192. 
Nilai ESAL Tahun 2031

Tabel 5. Nilai ESAL Tahun 2031 Jalan Rajawali dari Arah Segmen (Simpang 4

Tingang - Rajawali)

\begin{tabular}{|l|l|l|l|}
\hline Jenis Kendaraan & LHR 2031 & AE(VDF) & Nilai ESAL \\
\hline Sedan, pick up, angkot, wagon & 3810 & 0,0005 & 1,90500 \\
\hline Bus & 1 & 0,2174 & 0,32181 \\
\hline Truk & 37 & 2,4134 & 89,31054 \\
\hline \multirow{2}{*}{ Total } & $\mathbf{9 1 , 5 3 7 3 5}$ \\
\cline { 2 - 4 }
\end{tabular}

$(\mathrm{ESAL}) W_{18}=\sum_{N_{1}}^{N_{n}} L H R_{j} \times V D F_{j} \times D_{D} \times D_{L} \times 365$

ESAL W18 $=91,53735 \times 0,60 \times 0,8 \times 365$

ESAL $2031=\quad 16037,34293$

Tabel 6. Nilai ESAL Tahun 2031 Jalan Rajawali dari Arah Segmen (Simpang 4 Badak - Rajawali)

\begin{tabular}{|l|l|l|l|l|}
\hline No & Jenis Kendaraan & LHR 2031 & AE(VDF) & Nilai ESAL \\
\hline 1 & Sedan, pick up, angkot, wagon & 11451 & 0,0005 & 2,17152 \\
\hline 2 & Bus & 1 & 0,3006 & 0,32181 \\
\hline 3 & Truk & 118 & 2,4134 & 100,02780 \\
\hline \multirow{2}{nnnyy}{} & Total & $\mathbf{2 9 1 , 9 6 4 2 7}$ \\
\cline { 2 - 3 }
\end{tabular}

$(\mathrm{ESAL}) W_{18}=\sum_{N_{1}}^{N_{n}} L H R_{j} \times V D F_{j} \times D_{D} \times D_{L} \times 365$

ESAL W18 $=291,96427 \times 0,60 \times 0,8 \times 365$

ESAL $2031=\quad 17961,70146$

Dari tabel diatas maka didapat nilai ESAL 2031 untuk ruas jalan yang ditinjau yaiitu :

a. Nilai ESAL 2031 di ruas Jalan Rajawali dari Arah Segmen (Simpang 4 Tingang - Rajawali) adalah 16037,34293.

b. Nilai ESAL 2031 di ruas Jalan Rajawali dari Arah Segmen (Simpang 4 Badak - Rajawali) adalah 17961,70146.

\section{2) Nilai ESAL Kumulatif}

Umur rencana perkerasan dapat dianalisis berdasarkan hasil kumulatif ESAL pada masing masing skenario. Kumulatif ESAL dihitung per tahun mulai dari tahun pertama sampai akhir masa layan. Dari perhitungan akan didapatkan nilai kumulatif ESAL pada tahun pertama jalan dibuka yaitu tahun 2021 sampai dengan akhir umur rencana yaitu 2031. Analisis sisa umur pelayanan perkerasan didapatkan dengan membandingkan nilai ESAL pada tahun survai dengan nilai ESAL pada akhir umur rencana. Dari analisis ini akan didapat besar persentase umur sisa dari perkerasan. Berikut adalah nilai ESAL kumulatif tiap ruas jalan yang dapat dilihat pada tabel di bawah ini. Dengan menggunakan rumus diperoleh hasil sisa umur rencana jalan seperti tabel 7 berikut ini: 
Tabel 7. Nilai ESAL Komulatif Jalan Rajawali dari Arah Segmen (Simpang 4 Tingang - Rajawali)

\begin{tabular}{|l|l|l|}
\hline No & TAHUN & KOMULATIF ESAL \\
\hline 1 & 2021 & 10857,12648 \\
\hline 2 & 2031 & 16037,34293 \\
\hline$R L=100\left[1-\left(\frac{N_{p}}{N_{1,5}}\right)\right]$ \\
$R L=100 \times 1-\left(\frac{10857,12648}{16037,34293}\right)=66,95 \%$
\end{tabular}

Tabel 8. Nilai ESAL Komulatif Jalan Rajawali dari Arah Segmen (Simpang 4 Badak - Rajawali)

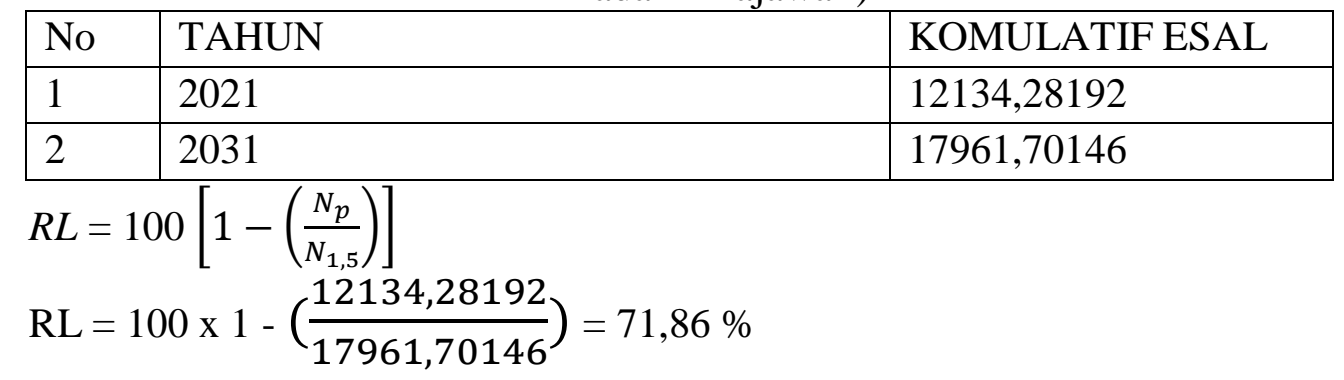

Dari tabel diatas maka didapat sisa umur rencana jalan untuk 10 tahun kedepan ruas jalan yang ditinjau yaitu :

a. Sisa umur rencana jalan di ruas Jalan Rajawali dari Arah Segmen (Simpang 4 Tingang - Rajawali) adalah sebesar $66,95 \%$

b. Sisa umur rencana jalan di ruas Jalan Rajawali dari Arah Segmen (Simpang 4 Badak - Rajawali) adalah sebesar $71,86 \%$

Yang artinya, pelayanan perkerasan pada tiap ruas jalan dalam 10 tahun kedepan berkurang. Hal ini terjadi karena beban yang melewati perkerasan jalan bertambah setiap tahunnya.

3) Nilai Derajat Kerusakan Jalan (DKJ) Dari Beban Overloading Pada Jalan Perencanaan kontruksi jalan didasarkan atas prakiraan beban lalu lintas yang melewatinya dengan mengkonversi satuan mobil penumpang (SMP), sesuai dengan fungsi jalan sebagai jalan nasional beban maksimum ditetapkan 10 ton, sehingga secara teoritis masa layanan dapat diperhitungkan.

Truk 2 sumbu $>20$ Ton

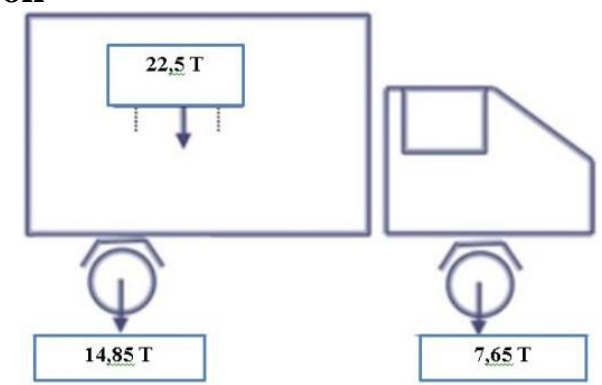

Gambar 1. Truk 2 Sumbu > 20 Ton 
DKJ roda bagian depan
$=\left(\frac{7,65}{10}\right)^{4}$
$=0,3424$
DKJ roda bagian belakang
$=\left(\frac{14,85}{10}\right)^{4}$
$=4,8630$
Jumlah
$=5,20$

Roda bagian depan termasuk aman karena nilainya kurang dari satu, sedangkan roda bagian belakang kelebihan 4,8630 sehingga menjadi tidak aman. Jadi truk tersebut mempunyai 2 as namun hampir sama 3-4 as tunggal yang lewat, berarti truk 2 as yang memiliki beban $>20$ ton tersebut overloading.

\section{Truk 3 sumbu > 30 Ton}

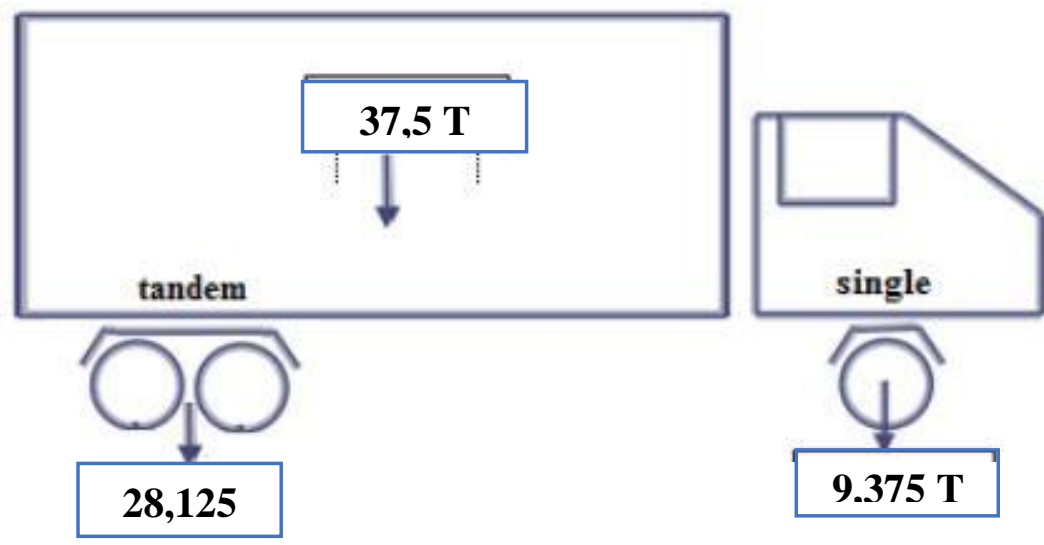

Gambar 2. Truk 3 Sumbu > 30 Ton
DKJ roda bagian depan
$=\left(\frac{9,375}{10}\right)^{4}=0,7724$
DKJ roda bagian belakang
$=0,086\left(\frac{28,125}{10}\right)^{4}=5,3810$
Jumlah

Roda bagian depan tidak aman karena nilainya lebih dari satu sedangkan roda bagian belakang kelebihan 5,3810 sehingga menjadi tidak aman. Jadi truk tersebut mempunyai 3 as namun sama dengan $3-4$ as tunggal yang lewat, berarti truk 2 as yang memiliki beban $>30$ ton tersebut overloading.

\section{Kesimpulan}

\section{PENUTUP}

Setelah dilakukan pengamatan dan penelitian pada ruas Jalan Rajawali diperoleh :

1. Berdasarkan hasil analisis sisa umur rencana jalan, pada ruas jalan Rajawali dari arah Segmen (Simpang 4 Tingang - Rajawali) mempunyai sisa umur yaitu 66,95 \% dan dari jalan Rajawali dari arah Segmen (Simpang 4 Badak Rajawali) mempunyai sisa umur yaitu $71,86 \%$.

2. Dari hasil perhitungan nilai derajat kerusakan jalan pada kendaraan, didapatkan bahwa truk 2 sumbu yang memiliki beban $>20$ ton mengalami overloading karena roda bagian belakang kelebihan 4,8630 sehingga menjadi tidak aman, yang artinya sama dengan truk yang memiliki 3 - 4 as tunggal yang lewat. truk 3 sumbu yang memiliki beban $>30$ ton juga mengalami 
overloading karena roda bagian belakang kelebihan 5,3810 sehingga menjadi tidak aman, dimana sama dengan truk yang memiliki 3 - 4 as tunggal yang lewat.

\section{Saran}

1. Berdasarkan hasil penelitian perlu adanya pemeliharaan dan perbaikan terutama pada badan jalan dari ruas jalan rajawali $\mathrm{km} 5$ untuk kedepan nya.

2. Agar tetap mampu melayani beban lalu lintas selama umur rencana 10 tahun atau bahkan bisa lebih dari 10 tahun, pengawasan harus tetap berjalan agar tidak terjadi pelanggaran muatan beban kendaraan yang lebih besar.

3. Pada perencanaan selanjutnya diperlukan metode/teori lain sebagai acuan dalam penelitian dengan area yang lebih luas atau yang lebih kompleks dengan masalah-masalah yang terjadi pada tinjauan selanjutnya.

\section{DAFTAR PUSTAKA}

AASHTO. 1993. AASHTO Guide for Design of Pavement Structure. Washington, D.C. $629 \mathrm{hlm}$.

Anggista, Randi, “Analisis Beban Kendaraan Terhadap Derajat Kerusakan Dan Umur Sisa Perkerasan (Studi Kasus : Jalan Lintas Sumatera Kecamatan Payung Sekaki)" Tugas Akhir Fakultas Teknik Universitas Lancang Kuning, Pekanbaru.

Arbani, Faisal Rifqi, “Analisis Kerusakan Dini Akibat Perubahan Volume Lalu Lintas Pada Perkerasan Lentur (Studi Kasis : Ruas Jalan Ahmad Yani Kartasura)'”. Tugas Akhir Fakultas Teknik Universitas Muhammadiyah, Surakarta.

Departemen Pekerjan Umum. 1987. Petunjuk Perencanaan Tebal Perkerasan Lentur Jalan Raya Dengan Metode Analisa Komponen.

Ditjen Binamarga. 2013. Manual Desain Perkerasan Jalan No 02/M/BM Tahun 2013. Kementerian Pekerjaan Umum. Jakarta.187 hlm.

Hardiyatmo HC. 2019. Perancangan Perkerasan Jalan Dan Penyelidikan Tanah. Yogyakarta: Gadjah Mada University Press.

Koestalam, P., Sutoyo. 2010, Perencanaan Tebal Perkerasan Jalan Jenis Lentur dan Jenis Kaku (Sesuai AASHTO, 1986 \& 1993).

Sukirman. S, 1996, Perkerasan Lentur Jalan Raya, Penerbit Nova, Bandung.

Willy, Morisca, "Evaluasi Beban Kendaraan Terhadap Derajat Kerusakan Dan Umur Sisa Jalan Studi Kasus : Ppt. Simpang Nibung Dan Ppt. Merapi Sumatera Selatan” Tugas Akhir Fakultas Teknik Universitas Sriwijaya, Sumatera Selatan. 